\title{
Factors of Knowledge Management and the Impact of Employee Turnover in Activity and Performance in Scientific and Technological Parks in Slovenia
}

\author{
Vasja Roblek \\ University of Primorska \\ Faculty of Management Koper, Slovenia \\ Zlatka Meško Štok \\ University of Primorska, \\ Faculty of Management, Koper, Slovenia
}

Maja Meško

maja.mesko@gmail.com

University of Primorska,

Faculty of Management, Koper, Slovenia

Ivan Erenda

TPV d.d., Kandijska cesta 60, 8000 Novo Mesto, Slovenia

vasja.roblek@gmail.com

zlatka.stok@fm-kp.si

\author{
(majamesko@gmail.com
}

ivan.erenda@gmail.com

\begin{abstract}
Technology parks provide infrastructure for the creation and development of knowledge-based organizations, which are associated with centers of technological excellence, mainly universities. This research addresses the question of management and skills acquisition in member organizations of technology parks in Slovenia. As means and lever for development organizations, we recognize the values and organizational culture, which cannot be achieved without employees who possess good knowledge. We associated knowledge management with employee turnover factor. The central purpose of this research is to focus on exploring the impact of movements in knowledge management on the turnover in organizations, which are members of technology parks. By using multivariate regression methods we confirmed that the required skills, knowledge acquisition and knowledge transfer channels, have a statistically significant effect on employee turnover in technology parks.
\end{abstract}

Keywords: Employee turnover, Knowledge management, Organizational culture, Technology parks

\section{Introduction}

What an organization needs for its survival and growth is a stimulating business and development environment. Technology parks are good examples of a business environment that enables organizations to develop and grow.

Park members are start-up organizations and organizations that have developed in the parks and continue their development path as an associate member. They are also referred to as graduated members. A common characteristic of technology parks is helping their members (start-up organizations) to establish optimal conditions for their development (organizational growth). Members provide overall leadership of the park, facilities, services (such as lectures, business links, etc...), and technological connectivity with centres of excellence and business environment, where multinationals and large companies can develop specific relationships with individual knowledge-based organizations, with the purpose of creating mutual benefits [8]. 
The main role of business-supporting infrastructure is visible especially in initiating partnerships with parallel support of information, counselling and education. What is particularly important is the reaction in the interaction with the environment in which it operates (partners, government authorities, investors, etc.). This means that the mass classical information passes into the custom-made information, as ordered by a known user or target group of users with high added value. Such information grows to specialist consulting and continuous user monitoring, while education is becoming more necessary in the areas of encouraging companies to work together, communicating on the types of cooperation and management in partner networks, within which a common style of management is developing, including overcoming market barriers and finally developing a joint economics and cultural network [2], [29].

Knowledge centres must be able to provide information and convert the data into knowledge, have market access and stress the importance of innovation. However, this does not mean that supporting institutions, such as the Technology Park or Centre of Excellence independently solve the complex problems of organizations. This merely means that support services organizations also need more knowledge, synergy and mutual cooperation [27].

\section{The Importance Of Organizational Structure For HPO Development}

For a successful development of a High Performance Organization (HPO), it is important that the internal structure of an organization aims to connect all HPO components. The organization thus promotes organizational learning and involvement of employees in the performance of functions and activities and their commitment to excellence management [28].

An important factor in the internal structure is an organizational culture that creates mindsets and reference frames, which are defined as one of the numerous important hidden processes. The meaning of the term 'culture' to a group is what 'personality' or 'character' present to an individual. In practice, we detect behaviour that leads to certain results, but often do not detect the forces that cause certain forms of behaviour [4]. This can be illustrated with an example of culture management and limiting behaviour of group members through sharing the same norms. In the 21 st century we are witnessing global warming and climate changes. Furthermore, we are looking for solutions within the concept of sustainable development, which will affect all cultural levels of contemporary organizations, whose task will be a close relationship with global challenges. Private organizations will need to reconsider how environmental responsibility fits into their basic concept of development and this will also affect the organizational culture [4], [27]. Eco-friendly countries are increasingly putting more value on social indicators which measure corporate social responsibility. They measure the level of readiness a corporation is willing to take to carry out environmentally-protective activities. Based on past investments in eco-projects, the agencies that calculate social indicators make their assessments on the basis of business plans, future investments in companies' management organizations into environmentally friendly projects. According to ecological indicators the socially conscious investors get the information which organization behaves in a socially responsible manner. Low social indicators undermine the effectiveness and reputation of the organization. The most widely used indicators for measuring the environmental efficiency, Kinder, Lydenberg, Domini Research \& Analytics (KLD) [9].

One should not forget that each group consists of members coming from different social backgrounds, ethnic groups, countries, etc. All this affects the cultural structure of an organization [27].

An organization is an open system where we see a constant impact of the external environment, with an emphasis on the global and constantly changing customer and supplier expectations. The value of the external structure is shown in the form of the ability to resolve customers' needs and problems. Good name and customer-supplier relationships change through time [28].

External effects of an organization are reflected in the organizational efficiency, activity and importance in the field of R \& D of individuals and groups within the organization and the contribution of the organization to society. HPO components in a one-off contribution to 
the transformation of input into output include the involvement of all employees, independent work, teamwork, integrated manufacturing technology, organizational learning and management excellence.

The HPO organizational effectiveness is measured by financial indicators and the importance of quality for the members of the organization, and indicators such as satisfaction and commitment to the organization. The contribution of the organization to society comes in form of charitable contributions and humanitarian work of its managers and employees [28].

\section{Knowledge As Key To Business Prosperity}

Knowledge is recognized as the basis for competitiveness and as key to business success [13], [17], [22].

Nonaka [18] points out that the quantitative data capture on new knowledge - to increase efficiency, reduce costs and improve ROI (return on investment) - is not sufficient for knowledge management. He stresses the importance of rapid response to customer needs, creating new markets and offering innovative products. The creation of new knowledge is not merely a matter of objective information processing. The idea is that the creation of new knowledge depends on the exploitation of tacit knowledge, and often highly subjective knowledge of each employee within an organization [2], [5], [18], [25], [26], [32].

In addition to that knowledge we should also consider the so called explicit knowledge (knowledge gathered in official records, such as patents) and the importance of their mutual interaction in the development of new products or services [6], [18], [26].

Knowledge brings benefits to both owners and employees of an organization. The time saved by locating and accessing information makes the employees more productive in developing their own skills. Effective decisions, which are taken on the basis of quality knowledge through many sources of knowledge, tend to minimize stress and increase their credibility and value [7], [32].

An example of a start-up organization in Slovenia is a highly innovative and knowledgebased company Pipistrel Ltd. Its core competencies are: development of ultra light aircraft, which can carry up to four people and does not pollute the environment and an innovative engine that will use hydrogen as a propellant in the aviation industry.

Apple is a globally recognized brand, which was created as a garage business and is a highly technological and innovative company. At the end of the seventies and in the beginning of the eighties, Apple and its owner managed to develop a serious company from a start-up company. They launched products like the Apple II to the market of and began to build brand awareness.

On the basis of knowledge, innovation, forming a close-knit team of colleagues and taking into account current market conditions and competitors are the owners developed a high-tech and profitable organization - a phenomenon which is typical of Silicon Valley [14].

\section{The Emergence And Importance Of Turnover For The Organization}

In conjunction with knowledge management, organization personnel competences in the task, we focus on the turnover, which is a normal phenomenon in the organization. A turnover occurs when an employee leaves an organization and must be replaced. Employee turnover is defined as the level of staff departures from the organization. The higher value level can be distracting for the organization and is followed by the development of higher costs incurred to replace the outgoing people with new employees, who need time and education in order to learn about business processes, and integrate into the system with ease [3], [22], [28].

It has to be stressed that when there is an increase of voluntary turnover in an organization, it is a sign that something is wrong there. A certain level of turnover for an organization is positive and healthy. We talk about the positive fluctuation phenomenon, which means that unsuccessful and unsuitable employees leave the organization [10].

The vacancies they create with their departure from the organization are replaced with new employees who bring fresh knowledge, new ideas and creativity [1], [25]. 
The McKinsey survey [15] found that IT companies in the U.S., which are characterized by high turnover rates have learned to live with that fact and turned it into their advantage. Frequent staff changes allow them come up with new perspectives and ideas, to have good energy renewal and access to new social networks.

The results from the fourth survey on working conditions in the EU countries [30] show that a quarter of organizations have up to three percent turnover, which is a low result, and there almost a $39 \%$ of organizations with a high $10 \%$ or higher turnover. In Slovenia, there is a $24.1 \%$ of organizations that have a high turnover rate and the percentage of low turnover rate organizations is only slightly higher than the EU average. This data suggests a relatively slow-dynamic Slovenian labour market. A potential fluctuation can be speculated indirectly regarding work satisfaction. In $27 \mathrm{EU}$ countries there are $81 \%$ of people satisfied with their jobs, but in Slovenia, only $71 \%$.

Costs associated with the voluntary turnover, which include the search for new staff and their learning, impact on reducing the organization's performance, productivity loss and loss of social capital [3], [11], [24].

There are some indicators established for measuring employee contributions and expenses, as organizational funds resources, such as ROI, EVA, HVA and cost-benefit analysis, which allow the economic and statistical models to identify the costs and advantages associated with the staff activity specification [22].

The ROI gives us the estimated costs of human resources activities. You can also calculate the time period in which the investment will repay itself [3], [11], [25].

Financial capital costs are defined as interest, depreciation, amortization and cost of capital. The cost of human capital is defined as staff costs, support costs and staff costs of the replacement employees [12].

Causes and departures from an organization can be mitigated by the factors that influence the turnover and thereby improve the ROI (balancing priorities, improving communication, facilitating personal growth, recognition of employees, organizational culture, adequate pay and good practices to promote the development of human resources).

Because we believe that providing more and better knowledge management leads to higher performance and thus to greater employee satisfaction, we developed three main hypotheses: H1: The demand for knowledge has a statistically significant impact on turnover in technology parks; H2: Knowledge acquisition has a statistically significant impact on turnover in technology parks and H3: Paths to knowledge transfer have a significant positive impact on turnover in technology parks.

\section{Methodology}

\subsection{Sample Presentation}

We selected a random sample of 667 organizations for an observable population suitable for an empirical verification of hypotheses. The organizations are members or associate members of the Slovenian technology parks and incubators, listed in JAPTI's (Public Agency of the Republic of Slovenia for Entrepreneurship and Foreign Investments) record in Group A. A questionnaire was sent to all of these organizations.

The total number of all respondents is 387 . The sample includes 281 men (72.6 percent) and 106 women (27.4 percent).

The frequency distribution of educational structure shows that we have 128 graduates in the sample with before pre- Bologna university degree (33 percent), 82 master's degrees or specialists (21.3 percent), and 62 professional programs of higher education graduates (16 percent), 58 Bologna masters or specialists (14.9 percent), 29 graduate colleges ( 7.4 percent), and 28 respondents, who had completed secondary school education (7.2 percent).

A high percentage of high educational level is justified by the fact that the survey took place in organizations that are members of the parks. Based on their membership and 
structure of the organizations, it is believed that the majority of the members are associated with high-tech activity that requires skilled personnel.

The respondent age analysis was done by using descriptive statistics for proportional variables. Clearly the age range goes from 26 and 60 years of age, with the average of 34.34 years. The standard deviation had a value of 7.811 .

There are new organizations being set up by students, young graduates and researchers in technology parks incubators, to which we can attribute a relatively young population of respondents.

The survey was conducted to grasp information on the structure of the organizations which is shown in Table 1.

\begin{tabular}{|l|r|r|}
\hline Business structure & Frequency & Percent \\
\hline Information technology & 78 & 30,524 \\
\hline Gambling machine manufacture & 1 & 0,26 \\
\hline Telecommunications and mobile telephony & 37 & 14,762 \\
\hline Research and development & 58 & 20,062 \\
\hline Services and development & 53 & 18,862 \\
\hline Business processes automation & 5 & 1,29 \\
\hline Hydraulic rotary pliers manufacture & 1 & 0,26 \\
\hline Advertising & 7 & 1,81 \\
\hline Biotechnology & 6 & 1,55 \\
\hline Genetics & 2 & 0,52 \\
\hline Medical equipment development & 5 & 3,9 \\
\hline In total & 363 & 93,8 \\
\hline Missing & 24 & 6,4 \\
\hline In total & 387 & 100 \\
\hline
\end{tabular}

Table 1. Business organizational structure.

\subsection{Research Instruments}

A survey questionnaire was designed, which consists of seven sets of closed and open questions regarding knowledge management. The first five sets are linked to knowledge management processes. A questionnaire on the knowledge management framework processes consists of 120 statements, to which there are possible answers of agreement on an ordinal scale. Closed questions are measured by a four-point Likert scale, with which the respondents gave the degree of agreement / disagreement with the proposed statement. The scale has a range from 1 to 4 (1 - strongly agree; 2 - agree; 3 - disagree; 4 - strongly disagree). Outstanding issues will be analyzed qualitatively.

The sixth set is devoted to issues concerning the fluctuation of personnel in the organization. In the seventh set there is a series of demographic questions (gender, age, education, work and activities).

\subsection{Research Process}

We started with the survey on March 3rd 2011 and finished March 24th 2011. We have created a web questionnaire for data collection. A link to the survey questionnaire was sent in the first week of March 2011 to email addresses. We provided anonymity for all who responded.

\subsection{Data Analysis Methods}

A basic survey overview of results is presented using descriptive statistics (tables, graphs). All hypotheses were tested at a significant rate, which is less than 5 percent $(\mathrm{P}=0.05)$. The 
Cronbach Alpha, which represents the coefficient of reliability or consistency, is used to verify the reliability of the questionnaire. The data was processed using the SPSS program.

By using multivariate regression analysis, we analyzed the relationship between the dependent variable and selected independent variables. The dependent variable represents a staff turnover in member organizations in the technology parks. Based on the given independent variables from the questionnaire, we selected those that can affect the turnover rate the most.

\section{Results}

\subsection{Turnover Rate Calculation}

Turnover rate is calculated based on the following formula: $\mathrm{EF}=\mathrm{O} * \frac{100}{\mathrm{SZ}+\mathrm{S}}$, (1)

$\mathrm{EF}$ is the share of turnover (in \%), $\mathrm{S}$ is the number of new employees, NW stands for the initial state of the workforce and $\mathrm{O}$ is the number of employees who have left the organization.

Based on the calculated turnover rates we can categorize the respondents according to the turnover rate into four groups (Table 2).

\begin{tabular}{|l|r|}
\hline Groups (according to the turnover rate) & Frequency \\
\hline $0-25$ & 39 \\
\hline $26-50$ & 7 \\
\hline $51-75$ & 1 \\
\hline $76-100$ & 4 \\
\hline
\end{tabular}

Table 2. Turnover rate in organizations.

Relatively high turnover rates are explained by the fact that the organization in question is a micro organization, founded by self-employed workers, who may change their status, so that within the organization they maintain the status of a managing director, while having a regular job at a different organization (business, science, education, etc.).

Different organizations gave various reasons for the emergence of fluctuations. 37 organizations ( 9.6 percent) reported voluntary termination of employment, termination due to failure to achieve the objectives was stated by 66 (17 percent), retirement is the reason alleged by 4 organization (1.1 percent), and conflict of interests between employees and the company have led to termination of employees in 29 organizations (7.4 percent), expiration of employment contract was the reason at 12 organizations ( 3.2 percent), and a lack of funds was the reason in 12 organizations (3.2 percent). 202 organizations (52.1 percent) gave was no reason for fluctuation and 25 organizations ( 6.4 percent) did not provide any reasons at all.

\subsection{Checking The Reliability Of The Questionnaire}

Cronbach alpha is a reliability and consistency coefficient. It is used to determine how well a group of variables or items measures an individual one-dimensional latent structure. Nunnaly's prescribed Cronbach's alpha of 0.70 was used as a guide for judging internal consistency In the case of a multi-dimensional structure the alpha coefficient is low [19], [21].

Based on the testing questionnaire we calculated the value of the Cronbach alpha: 0.819 to set the items on the knowledge requirements, 0.763 for the set of questions on the acquisition of knowledge and 0.715 for the set of questions on knowledge transfer. We conclude that the reliability of the questionnaire is good, because all alpha values go above the limit of the acceptability range (0.715) and extend to very high values above 0.80 as it goes for knowledge requirements (0.819). 


\subsection{Testing Hypotheses Using Regression Analysis}

We used the "enter" method, which includes all the variables and evaluates the regression coefficients for all independent variables simultaneously [15].

Hypothesis testing 1: The demand for knowledge has a statistically significant impact on turnover in technology parks (table 3 ).

\begin{tabular}{|c|c|c|c|c|c|}
\hline \multirow{2}{*}{ independent variables } & \multicolumn{2}{|c|}{$\begin{array}{l}\text { Unstandardized } \\
\text { coefficients }\end{array}$} & \multirow{2}{*}{\begin{tabular}{|c|} 
Standardized coefficients \\
Beta
\end{tabular}} & \multirow{2}{*}{ t statistics } & \multirow{2}{*}{ sig } \\
\hline & $\mathrm{B}$ & St. error & & & \\
\hline Technology influence & $-0,623$ & 0,337 & $-0,469$ & $-1,841$ & 0,000 \\
\hline Human influence & $-0,625$ & 0,41 & $-0,521$ & $-1,522$ & 0,000 \\
\hline $\begin{array}{l}\mathrm{R}^{2}=48,4 \% \\
\mathrm{~F}=89,06 \\
\mathrm{p}<0,01\end{array}$ & & & & & \\
\hline
\end{tabular}

Table 3. Display regression coefficients - requirements for knowledge.

$\mathrm{R}^{2}$ represents the adjusted coefficient of the explained variance, which in our case, is $48.4 \%$. The proportion of the explained variance in our model is $48.4 \%$, which means that the dependent variable is well explained with the selected independent variables.

By using F statistics, we tested the full regression model. We measured the purpose and meaning of the overall model. We got $\mathrm{F}=89.06$. We assess that this is a good model, which enables good data accommodation and is statistically significant.

An impact of both independent variables is statically significant. The standardized regression coefficients reveal that the fluctuation is by far mostly affected by the human factor. An increase of independent variables reduces turnover.

Hypothesis testing 2: The knowledge acquisition has a statistically significant impact on turnover in technology parks (table 4).

\begin{tabular}{|l|c|c|c|c|c|}
\hline \multirow{2}{*}{ independent variables } & \multicolumn{2}{|l|}{$\begin{array}{l}\text { Unstandardized } \\
\text { coefficients }\end{array}$} & Standardized coefficients & t statistcs & \multirow{2}{*}{ sig } \\
\cline { 2 - 5 } & B & St. error & Beta & & \\
\hline Technology Influence & $-0,118$ & 0,424 & $-0,341$ & $-1,356$ & 0,000 \\
\hline Human influence & $-0,167$ & 0,904 & $-0,47$ & $-1,510$ & 0,000 \\
\hline $\begin{array}{l}\mathrm{R}^{2}=43,6 \% \\
\mathrm{~F}=78,26 \\
\mathrm{p}<0,01\end{array}$ & & & \\
\hline
\end{tabular}

Table 4. Regression coefficients - the knowledge acquisition.

$\mathrm{R}^{2}$ represents the adjusted coefficient of the explained variance, which in our case, is $43.6 \%$. The proportion of the explained variance in our model is $43.6 \%$, which means that the dependent variable is well explained with the selected independent variables.

By using F statistics, we tested the full regression model. We measured the purpose and meaning of the overall model. We got $\mathrm{F}=78.26$. We assess that this is a good model, which enables good data accommodation and is statistically significant.

An impact of both independent variables is statically significant, the standardized regression coefficients reveal that the fluctuation is by far mostly affected by the human factor. An increase of independent variables reduces turnover.

Hypothesis Testing 3: Paths to knowledge transfer have a statistically significant impact on turnover in technology parks (table 5). 


\begin{tabular}{|l|c|c|c|c|c|}
\hline \multirow{2}{*}{ independent variables } & \multicolumn{2}{|c|}{$\begin{array}{c}\text { Unstandardized } \\
\text { coefficients }\end{array}$} & Standardized coefficients & \multirow{2}{*}{ t statistics } & \multirow{2}{*}{ sig } \\
\cline { 2 - 5 } & $\mathrm{B}$ & St. error & Beta & & \\
\hline impact of internal factors & $-0,416$ & 0,267 & $-0,311$ & $-1,356$ & 0,000 \\
\hline impact of external factors & $-0,435$ & 0,254 & $-0,275$ & $-1,714$ & 0,000 \\
\hline $\begin{array}{l}\mathrm{R}^{2}=30,4 \% \\
\mathrm{~F}=70,61 \\
\mathrm{p}<0,01\end{array}$ & & & \\
\hline
\end{tabular}

Table 5. Regression coefficients - the factors affecting knowledge transfer.

$\mathrm{R}^{2}$ represents the adjusted coefficient of the explained variance, which in our case, is $30.4 \%$. The proportion of the explained variance in our model is $30.4 \%$, which means that the dependent variable is well explained with the selected independent variables.

By using F statistics, we tested the full regression model. We measured the purpose and meaning of the overall model. We got $\mathrm{F}=70.61$. We assess that this is a good model, which enables good data accommodation and is statistically significant.

An impact of both independent variables is statically significant; the standardized regression coefficients reveal that the fluctuation is by far mostly affected by the human factor. An increase of independent variables reduces turnover.

\section{Conclusion and Discussion}

The primary purpose of the survey was to provide facts, which would explain how knowledge management affects the employees within State parks, creativity processes, innovation and employee satisfaction at work, as a means of knowledge as defined by Nonaka [19] as the organization-specific resources, which are essential for the creation of an organization.

Furthermore, survey was done to identify the development of a conceptual framework for understanding the impact of knowledge management on turnover in organizations that are members of the Slovenian technology parks.

We conducted a survey in which we are used a survey questionnaire to assess the impact of knowledge management on the turnover in 387 micro and small organizations, all members of the Slovenian technology parks.

We used multivariate regression methods and analyzed the influence of independent variables: hypothesis 1: the impact of technology, the human influence; hypothesis 2: the technology influence, the human influence; hypothesis 3 : Internal and external influences, and the dependent variable fluctuation. The three main hypotheses $\mathrm{H} 1, \mathrm{H} 2$ and $\mathrm{H} 3$, on the basis of which we confirm that knowledge management skills in micro and small organizations, members of Slovenian technology parks, have a typically positive turnover impact.

Organizations are exposed to competitive environment than with desire to succeed lead them to increase the production of knowledge. In doing so, organizations have different options. They can launch the knowledge to the market in the form of purchased licenses or franchises, acquired through acquisitions or to develop themselves.

Because of increasing globalization, an extremely rapid flow of information and industrial espionage is the only advantage the organization knowledge.

We find organizational knowledge in employees as well as through the ownership of patents, inventions, etc...

The success within the organization is to ensure the provision of business processes, which tend to be innovative, technology solutions and finding themselves in market needs. At the same should be aware of the importance of tacit knowledge and establish relationships with employees, which will tend to the common good.

Overall success will be guaranteed if both the organization and employees aware about the importance of acquisitions, both external and internal knowledge, the dissemination of knowledge throughout the organization and proper decision-making based on information that 
must be properly treated before they are based on them make important business and business decisions.

The aim of future research should be based on how the marketing, educational and entrepreneurial orientation guide and contribute towards the production of knowledge in the external and internal environment within the organization. It needs sources of knowledge and their impact on operations and growth of small and medium-sized organizations.

\section{References}

[1] Abelson, M.A.; Baysinger, B.D. Optimal and dysfunctional turnover: toward an organizational level model. Academy of Management Review, 9(2):331-341, 1984.

[2] Alavi, M.; Leidner, D.E. Review knowledge management and knowledge management systems: conceptual foundations and research issues. MIS QuaterlY, 25(1):107-136, 2001.

[3] Armstrong, M. Armstrong's handbook of human resource management practice. Kogan Page, London, 2009.

[4] Baskerville, R.; Dulipovici, A. The theoretical foundations of knowledge management. Knowledge Management Research \& Practice, 4(4):83-105, 2006.

[5] Bertoncelj, A.; Kovač, D.; Bertoncel, R. Success factors and competencies in organisational evolution. Kybernetes, 38(9):1508-1517, 2009.

[6] Bollinger, A.; Smith, R. Managing organizational knowledge as a strategic asset. Journal of Knowledge Management, 5(1):8-18, 2001.

[7] Chandra, P.; Srivastav, S.; Shah, B. Innovation, incubation, and incubator. Vikalpa, 28(2):89-94, 2003.

[8] Chatterji, A.K.; Levine, D.I.; Toffel, M.W. How well do social ratings actually measure corporate social responsibility? Journal of Economics \& Management Strategy, 18(1):125-168, 2009.

[9] Dalton, D.R.; Krackhardt, D.; Porter, L.W. Funkctional turnover: an empirical assessment. Journal of applied psychology, 66(6):716-721, 1981.

[10] Dess, G.G.; Shaw, J.D. Voluntary turnover, social capital and organizational performance. The Academy of Management review, 26(3):446-456, 2001.

[11] Di Bernardino, F.; Miller, A. Human capital analytics - the missing link: meausuring financial returns on the human capital investment. Vienna Human Capital Advisors, Radnor, 2008.

[12] Drucker, P. Post - capitalist society. Butterworth-Heinemann, Oxford, 1993.

[13] Groeger, M. http://www.silicon-valley-story.de/sv/apple.html, downloaded: November $1^{\text {st }} 2010$.

[14] Hoch, D.J.; Lindner, S.K.; Müller, R. Current research ... in Europe: a brief look at findings from recent McKinsey research projects, 2000.

[15] McKinsey. http://www.mckinsey quaterly.com/crweb/curx00.asp, downloaded: April $1^{\text {st }} 2011$.

[16] Kazmier, L.J. Schaum's outline of theory and problems of business statistics. McGraw-Hill, New York, 2004.

[17] Nonaka, I.; Takeuchi, H. The knowledge-creating company: How Japanese companies create the dynamics of innovation. Oxford University Press, Oxford, 1995. 
[18] Nonaka, I. The knowledge - creating company. In Harvard business review on knowledge management, pages 21-46, Peter F. Drucker, Harvard Business School Press, Boston, 1998.

[19] Nonaka, I.; Toyama, R.; Konno, N. Seci, Ba and leadership: a unified model of dynamic knowledge creation. Long Range Planning, 33(1):5-34, 2000.

[20] Nunnaly, J.C. Psychometric Theory. McGraw-Hill, New York, 1978.

[21] Mathis, R.L.; Jackson, J.H. Human resource management. Thomson/SouthWestern, Mason, 2004.

[22] Pahor, M. Introduction to PASW (SPSS) workshop. Faculty of Economics, Ljubljana, 2010.

[23] Pejić Bach, M.; Čerić, V. Developing System Dynamics Models with „, Step-bystep“ Approach. Journal of Information and Organizational Sciences, 31(1):171$185,2007$.

[24] Pemberton, J.D.; Stonehouse, G.H. Organisational learning and knowledge assetss - an essetnial partnership. The Learning Organization: An International Journal, 7(4):184-194, 2000.

[25] Phillips, J.J.; Edwards, L. Managing talent retention: an ROI approach. Wiley, San Francisco, 2008.

[26] Sanchez, R. Tacit knowledge versus explicit knowledge: approaches to knowledge management practice. Copenhagen Business School Press, Copenhagen, 2005.

[27] Schein, E.H. Organizational culture and leadership. Jossey-Bass, San Francisco, 2010.

[28] Schermerhorn, J.R.; Hunt, J.G.; Osborn, R.N. Organizational behavior. Wiley, New York, 2002.

[29] Srai, J. S.; Bertoncelj, A.; FLEET, D.; GREGORY, M.J. An operations process framework for international M\&A value creation. European journal of international management, 4/1/2): 3-29, 2010.

[30] Tan, J. Growth of industry clusters and innovation: lessons from Beijing Zhongguancun science park. Journal of Business Venturing, 21(5):827-850, 2006.

[31] Thirion Parent, A.; Macias, F.E.; Hurley, J.; Vermeylen, G. Fourth european conditions survey. European foundation for the improvement of living and working conditions, Dublin, 2007.

[32] Wang, Z.; Wang, N. Knowledge sharing, innovation and firm performance. Expert systems with applications, 39(10):8899-8908, 2012. 